\section{Considerações sobre a atenção domiciliária e suas aproximações com o mundo do trabalho na saúde}

\author{
Home care and its relationship to the work \\ environment in health
}

\footnotetext{
${ }_{1}$ Departamento de Enfermagem, Fundação Universidade Federal do Rio Grande, Rio Grande, Brasil. 2 Departamento de Enfermagem, Universidade Federal de Santa Catarina, Florianópolis, Brasil.

Correspondência N. P. C. Kerber Departamento de Enfermagem, Fundação Universidade Federal do Rio Grande.

Rua João Manoel 173, Rio Grande, $R S$ 96211060 , Brasil. nalu@vetorial.net
}

\begin{abstract}
This paper discusses home care as a service that has expanded in the public and private health system, while arguing for the possibility that such care can leverage a significant impact on the population's quality of life and health. The article presents home care as a strategic possibility for reorganizing the health system, by means of integration between health workers and health institutions, and considers its possible political, economic, and technical impacts on the health system, health workers, and users of the service.
\end{abstract}

Home Nursing; Health Systems; Health Personnel
Nalú Pereira da Costa Kerber 1,2

Ana Lúcia Cardoso Kirchhof 2

Marta Regina Cezar-Vaz 1

\section{Considerações iniciais}

O trabalho na saúde tem passado por muitas transformações, decorrentes da reorganização da economia mundial e da adaptação do mundo do trabalho a estas transformações 1,2,3,4,5. Entre elas pode-se citar a inovação tecnológica, a terceirização de serviços e a necessidade de qualificação dos trabalhadores. Isso tem provocado mudanças qualitativas no processo de trabalho, que apresentam aspectos positivos e negativos, pois, se por um lado, vêm no sentido de facilitar o trabalho, melhorar a assistência e qualificar a mão-de-obra, por outro, criam a necessidade de elaboração de um projeto social que reorganize essas transformações no cenário dos serviços e trazem um componente de aumento de competitividade por parte dos trabalhadores, que precisam esforçar-se cada vez mais por uma vaga no mercado de trabalho. Ou seja, o mundo do trabalho está continuamente sofrendo transformações, pois: "se o homem aceitasse sempre o mundo como ele é, e se, por outro lado, aceitasse sempre a si mesmo em seu estado atual, não sentiria a necessidade de transformar o mundo nem de transformar-se" 6 (p. 192).

O trabalho em saúde tornou-se essencial para a sobrevivência humana, abarcando muito mais cuidados, não apenas concernentes aos cuidados biológicos, mas incluindo outras dimensões das interações entre a vida humana e o ambiente. Ao profissional da saúde e instituições é exigida 
a realização de atividades que abarquem essas dimensões, a assistência à saúde, que é produzida no mesmo momento em que é consumida. Considerando o trabalho em saúde "essencial para a vida humana" 5 (p. 85), temos de considerá-lo como um trabalho que é desenvolvido não somente para satisfação pessoal do trabalhador, mas, também, para satisfazer necessidades de outras pessoas.

Ao refletir sobre essa questão em que o produto tem um alcance coletivo, pensamos que "há um desafio a ser considerado pelos profissionais para um maior êxito do trabalho em saúde: o desenvolvimento de uma práxis que se coloque necessária e apropriável pelo usuário do trabalho da saúde" 7 (p. 12). Ou seja, se reconhece que é da esfera do usuário a capacidade (ou não) de transformar esse trabalho sem um produto material, no caso um serviço, materializando-o no seu corpo e resultando em uma atividade efetiva.

Como um ser da práxis, o trabalhador de saúde, comprometido com os usuários dos serviços, avalia e revê continuamente o seu modo de fazer o trabalho, para que desta forma possa responder e atender às inúmeras e crescentes demandas que vão se apresentando no decorrer do desempenho do seu trabalho.

Acreditamos que os trabalhadores comprometidos com a saúde como um bem social, têm consciência da precarização dos serviços de saúde e do não atendimento das necessidades de uma parcela significativa de usuários e estão buscando novas formas de organização do trabalho em saúde que possam contemplá-la, como a atenção domiciliária. Entendemos esse tipo de estratégia como uma tentativa para buscar assegurar a assistência contínua à população, a qual anseia por uma atenção que não tem sido possível de ser ofertada por meio das modalidades existentes, que são práticas individualistas como as desenvolvidas no interior das instituições hospitalares ou, mesmo em algumas unidades da rede básica de serviços de saúde, ainda aliadas a uma resolutividade parcial das ações, uma vez que não apresentam um cuidado integral e contextualizado.

A atuação tradicional do setor saúde conduz à compreensão do indivíduo como isolado de seu contexto familiar e de valores sócio-culturais. Essa tendência generalizante fragmenta e massifica o indivíduo no sistema. Ele é visto como manifestação da doença que ocorre em partes de seu corpo, sem que sejam observadas suas diferentes dimensões, e acaba submetendo-se a vários serviços de saúde que o atendem de forma impessoal, diminuindo a possibilidade de estabelecimento de vínculo entre usuário, serviço e terapêutica. Como conseqüência os resultados de uma relação assim tendem a ser muito deficitários, pouco resolutivos e implicam sobretrabalho, ao remeter esse indivíduo para uma outra porta de entrada no sistema.

De fato, diante dessa forma de atenção à saúde, acreditamos que há pouca resolutividade dos serviços de saúde e, neste aspecto, visualizamos deficiências, como a descontextualização da assistência, o que proporciona pouca segurança e tranqüilidade para a clientela. Por entender a relevância da discussão dessas questões, este estudo tem como objetivo refletir acerca da atenção domiciliária como uma prática em saúde que se apresenta como possibilidade de uma maior resolutividade dos serviços de saúde.

No entanto, a fim de melhor conhecer como a atenção domiciliariavemsendocompreendidana literatura brasileira e internacional, fizemos uma busca nas bases de dados LILACS e MEDLINE, no período de 1994 a 2004, utilizando como descritores: serviços de assistência domiciliar, serviços de assistência hospitalar no domicílio, auxiliares de cuidado domiciliar e serviços hospitalares de assistência domiciliar. Foram selecionados textos que contemplassem uma discussão conceptual/operacional acerca da atenção domiciliária, que passamos a apresentar.

\section{As concepções e tendências acerca da atenção domiciliária em estudos brasileiros e internacionais}

Por meio do trabalho o homem produz e reproduz sua existência. Nesse trabalho estão incluídas as práticas de saúde que, segundo Almeida \& Rocha 8 (p. 24), são compreendidas, na concepção histórica, materialista e dialética como “articuladas ao modo de produção, às políticas sociais, parte de um processo de trabalho histórico, coletivo, organizado socialmente para atender aos carecimentos sociais".

A partir dessa compreensão acerca da conformação das práticas de saúde fortemente ligadas às questões sociais, políticas e econômicas, pode-se entender o rumo tomado pelas diversas apresentações que tem o trabalho atualmente; uma destas práticas, que vem se consolidando pouco a pouco nas realidades de trabalho, é a atenção domiciliária. Nessa prática podem ser agregados tanto o processo de trabalho cuidar quanto o educar, conforme a necessidade gerada em cada momento da ação propriamente dita. A abordagem acerca desses tipos de processos de trabalho, cuidar e educar, tem sido feita por diversos autores, como Castellanos et al. 9, Leopardi et al. 10 e Kirchhof 7, sendo processos que se mesclam e interagem, e 
vão conformando o ato do trabalho em si, a prática da atenção domiciliária. O termo atenção domiciliária envolve algumas concepções que precisam ser elucidadas neste momento, para que se possa compreender como se processa este tipo de estratégia nas realidades em que é implementada.

Existe uma ampla produção acadêmica sobre o assunto, embora a produção internacional apresente-se de forma metodologicamente mais organizada e explorada. Em nível nacional, o volume de estudos envolvendo o termo atenção domiciliária - ou outra das denominações indicativas de um tipo de prática realizada no domicílio - ainda é pequeno. Autores como Fialho et al. 11 focalizaram sua atenção na adequação da Teoria do Déficit do Autocuidado à prática do cuidado domiciliar. Silva \& Aguillar 12 centraram-se na análise dos problemas apresentados por pacientes submetidos à quimioterapia antineoplásica. Paskulin \& Dias 13 e Kerber et al. 14, na percepção dos clientes. Enquanto Lacerda 15 e Silva et al. 16 detiveram-se nos desafios das relações interpessoais e interprofissionais na internação domiciliar.

Na revisão sobre esta temática, ainda visualizamos lacunas que consideramos necessário ser preenchidas devido à importância desse tipo de trabalho, já que este vem se mostrando com um futuro promissor, como afirmam Hirschfeld \& Oguisso 17 (p. 456): "iniciado no final do século $X X$, o home care irá firmar-se definitivamente no século XXI e passará a ampliar cada vez mais seu espaço, como uma das especialidades para todos os profissionais da saúde, mas, sobretudo para enfermeiros e pessoal de enfermagem". Percebemos a necessidade de ser efetuado um número maior de estudos, englobando a relação custobenefício, a satisfação do cliente e da família, a eficácia e a efetividade desse tipo de assistência, as vantagens e as desvantagens para um estabelecimento de saúde vir a incorporar como parte de seus serviços a atenção domiciliária.

Em termos de denominações e descritores, na literatura encontrada, despontam: visita domiciliária programada, home care, internação domiciliária, assistência domiciliária, atenção domiciliária. Todos significam o cuidado desenvolvido no espaço domiciliar. O que os diferencia é a complexidade desse cuidado, o que não significa, necessariamente, a utilização de equipamentos de tecnologia avançada, podendo estar atrelada a uma maior periodicidade no acompanhamento do paciente, como no caso da internação domiciliária que, segundo LópezBenito \& Baydal 18 (p. 678), é "o conjunto de tratamentos e cuidados sanitários proporcionados no domicílio de uma complexidade, intensidade e duração comparáveis às que receberia esse mesmo paciente no hospital convencional".

De forma semelhante, Sherpperd \& Iliffe 19 referem-se a essa modalidade assistencial, chamando de hospital em casa, como sendo a provisão de um serviço que previne a admissão hospitalar ou facilita a alta do hospital. Outros autores que também se referem à provisão de serviços e atenção especializada no domicílio, quando o hospital já cumpriu sua missão, são Trujillo et al. 20, porém, estes dão um enfoque preventivo, além do curativo e de reabilitação. Isso significa que eles ressaltam o papel da educação na redução dos fatores de risco para doenças crônico-degenerativas e a detecção oportuna de patologias, o que não é sinalizado pelos primeiros autores citados, que se referem a uma assistência com enfoque clínico-individual.

Em relação ao termo atenção domiciliária, Ramallo et al. 21 (p. 659) manifestam-se como sendo "o conjunto de atividades assistenciais, sanitárias e sociais que se desenvolvem no domicílio". Carletti \& Rejani 22 exploram um pouco mais esse termo, definindo-o como um serviço em que são desenvolvidas ações de saúde no domicílio do cliente por uma equipe interprofissional, a partir da realidade em que o mesmo está inserido, visando à promoção, manutenção e/ou restauração da saúde, e desenvolvimento e adaptação de suas funções de maneira a favorecer o restabelecimento de sua autonomia.

O Município de São Paulo tem um programa denominado Assistência Domiciliar, com a concepção de que "é uma forma de atendimento ao paciente no domicílio, que procura conciliar os meios disponíveis nos diversos equipamentos de saúde, com os recursos e necessidades da comunidade a ser atendida" 23 (p. 5).

Como se pode observar, as concepções do termo parecem entender essa assistência como contextualizada, humanizada e resolutiva. Uma das conceituações mais abrangentes encontradas na literatura foi na leitura das Normas de Organização e Funcionamento de Serviços de Internação Domiciliária para a República Argentina, que trazem a concepção da Internação Domiciliária como uma área, e esta área como: "uma modalidade de atenção à saúde mediante a qual se presta assistência ao paciente-família em seu domicílio, realizada por uma equipe multiprofissional e interdisciplinar cuja missão é: promover, prevenir, recuperar, reabilitar elou acompanhar aos pacientes de acordo com seu diagnóstico e evolução nos aspectos físico, psíquico, social, espiritual, mantendo a qualidade, o respeito e a dignidade humana" 24 (p. 26).

No Brasil, hoje, a denominação visita domiciliária nos remete imediatamente ao Programa 
Saúde da Família (PSF), por ser esta uma atividade bem difundida e apregoada neste modelo de atenção à saúde. Fracolli \& Bertolozzi 25 , que se detiveram no estudo acerca do PSF, fazem referência à visita domiciliária como um instrumento de intervenção que possibilita uma aproximação com os determinantes do processo saúde-doença no âmbito familiar.

É importante que seja ressaltado, neste momento, que as visitas domiciliares não são novidade e nem exclusividade do PSF por serem um recurso que pode ser utilizado por qualquer estabelecimento de saúde. De acordo com Franco \& Merhy 26 , a visita domiciliar é própria da missão das Unidades de Saúde e deve ser considerada um expediente rotineiro em serviços assistenciais.

Pensamos que a visita realizada no PSF se configuraria como uma prática de atenção domiciliária quando utilizada de forma planejada e sistematizada, com propósitos investigativos que subsidiem ações futuras. Portanto não é uma prática com finalidade apenas imediata.

Qualquer que seja a denominação assumida e as atividades desenvolvidas, cada uma dessas designações encerra uma prática de saúde voltada para um objeto que tanto pode ser o sujeito individual quanto se estender para além do indivíduo, abrangendo suas diferentes dimensões. Percebemos essa aproximação conceitual no texto de Maidana 24, o qual salienta a importância do elemento familiar no processo de trabalho em saúde no contexto domiciliar. A atenção à saúde não pode ser direcionada a um só indivíduo, pois a questão coletiva ultrapassa a individual, ao mesmo tempo em que a inclui, ou seja, inúmeras vezes partimos do indivíduo como objeto de nossa assistência, porém, não perdendo de vista o contexto familiar e social, tornando estas dimensões parte constante do nosso foco da atenção no trabalho.

A concepção de atenção domiciliária, que pressupomos como ideal e possível de ser desenvolvida pelos trabalhadores em saúde é a de uma prática do trabalho em saúde, que visa a assistir ao indivíduo e à família no espaço domiciliar, de forma integral e contextualizada, nos aspectos de promoção, prevenção, recuperação e reabilitação, promovendo uma integração dos diversos trabalhadores atuantes no Sistema de Saúde para oferecer cuidado de saúde de acordo com as possibilidades do serviço e as necessidades do cliente.

\section{A atenção domiciliária como estratégia de suporte para a reorganização do Sistema Único de Saúde}

Consideramos que são muitos os fatores que têm contribuído para o desenvolvimento de propostas de atenção domiciliária no país. Um deles é a mudança de direção pela qual vem passando o sistema de saúde, com ênfase no cuidado aos pacientes crônicos como base do sistema primário de cuidado à saúde, anteriormente direcionado aos cuidados agudos 27 . A idéia é que à instituição hospitalar sejam orientados apenas os pacientes com necessidades de cuidados agudos, permanecendo os doentes crônicos com a assistência prestada no domicílio. No entendimento de alguns autores citados, essas mudanças, muito provavelmente, estejam pautadas na intenção de redução dos custos do sistema de saúde e de incremento do conforto e da privacidade oferecidos no domicílio.

Entendemos essa justificativa como uma medida de escape da crise que acomete os hospitais públicos, sem espaço físico suficiente para atender à demanda. Outros fatores são ressaltados por Santos et al. 28: o novo padrão demográfico brasileiro, que aponta para o envelhecimento da população; as mudanças no perfil epidemiológico, caracterizado pelo aumento das doenças crônico-degenerativas e infecciosas e, conseqüente, aumento do risco de complicações e do nível de dependência; a inadequação do sistema atual de saúde para atender às demandas da população; a adoção pelo governo de programas de extensão de cobertura com atenção à família; a busca por alternativas de aumento de renda familiar que transferem as funções de cuidado para outras instituições.

Um exemplo desses fatores, a inadequação do sistema de saúde atual no atendimento das demandas da população, pode ser percebido ao se contemplar a situação vivenciada nas instituições hospitalares públicas. Esses hospitais não têm dado conta de assistir à clientela que os procura, ansiosa por internação. Ao visitar as emergências, pode-se vislumbrar um infindável número de sujeitos enfermos espalhados em macas pelos corredores e aguardando uma vaga em unidades de internação.

Sabemos que o modelo assistencial hegemônico em saúde, que tem uma construção histórica e social, privilegia intensamente as ações curativas, individuais, hospitalocêntricas, com intervenções medicalizantes.

Esse aspecto foi trazido, neste momento, para reforçar a necessidade de medidas alternativas que auxiliem os hospitais a desenvolverem suas atividades de forma mais adequada a uma neces- 
sária mudança de modelo assistencial. Segundo Cecílio 29 (p. 12), “...é possível e necessário explorar estratégias de desconcentração do atendimento hospitalar. Os programas de internação domiciliar, de visita domiciliar ou do médico de família, com suas abordagens diferenciadas, reforçam este necessário movimento desconcentrador". Porém, somente sair do hospital para o domicílio, sem mudar o processo de trabalho que caracteriza e conforma esse modelo hegemônico não resolverá essa situação. Apenas mudará o local de atendimento. Pereira 30 defende que o domicílio proporciona potência para os trabalhadores fazerem uma reflexão sobre a concepção do processo saúde-doença, sobre a concepção de ser humano, enfim, refere que o domicílio possibilita reconhecer o paciente em suas múltiplas relações.

Parece que uma vantagem da atenção domiciliária está posta na possibilidade de oferecer uma assistência de qualidade com custos razoáveis, fazendo com que ela se apresente, em algumas ocasiões, como uma parte da solução aos problemas financeiros dos sistemas de saúde, reduzindo a hospitalização e o tempo prolongado de internação, ao mesmo tempo em que pretende melhorar a qualidade de vida da população a que se dirige 31 .

Em primeira instância, é possível compreender a atenção domiciliária como uma estratégia a este caos em que se encontram os hospitais. Seria uma tentativa de amenizar a relação "sujeitos necessitados de assistência/trabalhadores/serviços de saúde", que se encontra bastante comprometida pelo fato da demanda ser muito maior do que a oferta. Os trabalhadores da saúde angustiam-se com essa situação, questionando a qualidade desse trabalho, já que precisam assistir a uma grande quantidade de enfermos em condições precárias. Por esse prisma, a atenção domiciliária é uma alternativa que está sendo bem aceita e considerada mais humanizadora devido à possibilidade de o paciente estar junto à família, de o familiar que efetua o cuidado não precisar abandonar seus outros afazeres para permanecer no hospital, e a segurança que teriam com um profissional prestando-lhes assistência no domicílio 14 .

Muito mais do que amenizar a relação entre clientes/trabalhadores/instituição de saúde, a atenção domiciliária encerra uma possibilidade para além disto, compondo uma estratégia reorganizacional da atenção à saúde.

A atenção domiciliária pode vir a ser uma estratégia viável e que pode ajudar, tanto na resolução da problemática enfrentada pela população carente de atenção à sua saúde, quanto colaborar com as instituições públicas de serviços de saúde. Essas instituições têm a possibilidade, por meio da atenção domiciliária, de expandir seus serviços e obter um maior alcance de suas ações. Pode ser considerada uma proposta de grande relevância nesse sentido e, ainda, auxiliar o trabalhador da saúde na tentativa de romper com uma prática clínico-individualista, a qual não percebe o sujeito/objeto de trabalho de uma forma integral, tanto em nível hospitalar quanto na rede básica de serviços de saúde.

O domicílio foi considerado por Furtado 32 como um ambiente que proporciona maior viabilidade e ressonância para o agir além das questões estritamente médicas e técnicas, possibilitando agregar as dimensões emocionais e afetivas. E, com uma grande vantagem, que é a possibilidade de integrar os trabalhadores de ambos os espaços de serviços, como hospitais e rede básica, já que há a probabilidade de que um trabalho conjunto possa ser efetuado, e não somente em nível de referência e contra-referência, mas no compartilhar de responsabilidades.

"Hemos de reconocer, sin embargo, el papel primordial que tiene la atención domiciliaria en la potenciación de la coordinación e integración de los servicios sanitarios y sociales, ya que permite compartir responsabilidades clínicas, organizativas e financieras, y superar la tradicional provisión dicotómica de la asistencia, con lo que puede constituirse en un elemento facilitador e impulsor de una progresiva conexión entre el hospital y la atención primaria" 33 (p. 258).

Essa é uma necessidade manifestada no cotidiano do trabalho em saúde, já que há uma dicotomia que permeia as diversas práticas de trabalho existentes, como no caso do trabalho realizado em instituições hospitalares e nas unidades básicas de saúde. Cada trabalhador desenvolve o seu trabalho isolado, no interior da sua instituição, sem estabelecer relações fora deste espaço, restringindo o seu campo de ação.

Com base nessas reflexões, se reconhece a atenção domiciliária como uma possibilidade de integração dos trabalhadores atuantes em instituições hospitalares com os trabalhadores atuantes na rede básica de serviços de saúde. Essa assertiva a visualiza como uma prática que pode se desenvolver em vários momentos, com diversos trabalhadores e não sendo do domínio nem da equipe de atenção primária, nem da de atenção hospitalar, uma vez que há um espaço de assistência que pode ser orientado para cada uma destas equipes ou para ambas. Nesse espaço de trabalho dessas equipes, há a possibilidade de integração dos trabalhadores, que podem conjuntamente compartilhar momentos da assistência e estabelecer o plano da continuidade de atendimento. Ele é entendido aqui como o momento em que a atenção domiciliária começa 
a ser repassada de uma instituição de saúde a outra. Por exemplo, um cliente que recebe alta hospitalar para continuidade do tratamento em nível domiciliar e que este cuidado é realizado inicialmente pela equipe de atenção domiciliária do hospital; após estabilização do quadro clínico, a equipe de atenção domiciliária da rede básica de saúde pode assumir o cuidado. Há um compartilhamento no planejamento do cuidado posterior pelas duas equipes e a hospitalar pode ser novamente acionada, caso necessário.

O papel primordial que pode ter a atenção domiciliária na capacidade de coordenação e integração dos serviços pode ser defendido, já que permite compartilhar responsabilidades, facilitar e impulsionar a conexão entre hospital e outros níveis de atenção, como já ressaltado por Cotta et al. 33

A atenção domiciliária seria um instrumento com potência para produzir uma assistência comprometida com o estabelecimento de uma relação de vínculo trabalhador/usuário, de promoção do acolhimento e desenvolvimento de co-responsabilidade, direcionando assim para os propósitos do SUS. O PSF, por meio dela, poderia articular-se aos demais estabelecimentos de saúde para desenvolverem de forma integrada esse tipo de atividade, visando à prestação de um cuidado mais completo, ou seja, integral e resolutivo.

A atenção domiciliária, como instrumento de intervenção no PSF, na proposta de atenção à família, já é amplamente apregoada pelo sistema. Porém, essa prática, como um trabalho que pode ser desenvolvido por qualquer instituição prestadora de serviços de saúde, ainda é incipiente, estando na fase embrionária como política pública no Brasil, existindo apenas algumas experiências isoladas que servem como modelo de atuação, como em Porto Alegre, no Rio Grande do Sul, em Londrina, no Paraná e em Santos, em São Paulo.

Essa forma de atenção foi incorporada por poucas instituições públicas de saúde como um serviço, permanecendo pouco difundida e operacionalizada. Ela já está regulamentada, seja no setor público, no qual foi instituída pela $L e i$ Complementar $n^{\circ}$. 10.424, de 15 de abril de 2002, que veio acrescentar o Capítulo VI e o artigo 19-I à Lei $n^{o}$. 8.080, de 19 de setembro de 1990, seja no setor privado, com a regulamentação da Agência Nacional de Saúde (ANS) - para os planos de saúde, com o Projeto de Lei $n^{\circ}$. 7.417/2002, o qual modifica a Lei $n^{\circ}$. 9.656/98, que trata dos planos de seguro privado de saúde 34 .

Assim, a atenção domiciliária pode ser uma prática permanente do trabalho em saúde, realizada não só no interior dos PSF, mas, também, como uma expansão da assistência hospitalar, compondo uma alternativa para o enfrentamento da crise no setor da saúde, o que pode ser efetuado por meio de programas de atendimento domiciliário, desenvolvido tanto nos âmbitos público quanto privado. Por isso, é uma estratégia de cuidado que valoriza e potencializa o domicílio como um espaço de cuidado.

Sob esse prisma, este trabalho pode colaborar tanto com as instituições públicas de saúde, na expansão de seus serviços e obtenção de um alcance maior de suas ações, quanto ajudar na resolução da problemática enfrentada pela população carente de atenção à sua saúde, ao reconhecer o domicílio como um espaço de cuidado, valorizando os recursos físicos e ambientais e o apoio familiar como importantes no cuidado ao cliente dos serviços de saúde. Ou seja, ao reconhecer esse ambiente também como próprio ao cuidado, o setor saúde abre mão de alguns pressupostos que restringiam apenas os serviços de saúde como apropriados ao ambiente de cuidado por profissionais de saúde. Muito embora o domicílio já tenha sido reconhecido como um ambiente de cuidado, isto não o incluía como espaço de cuidado profissional, como vem ocorrendo nas experiências referidas anteriormente.

A principal vantagem dessa modalidade de trabalho é o fato de estar e de cuidar na família e no domicílio, que passam a ser vistos como influenciadores na melhoria da qualidade de vida do paciente e dos envolvidos no processo, evitando que o doente perca o vínculo familiar e seu meio social e cultural ${ }^{34}$.

Isso requer uma visão integralizada, com foco assistencial na família e não somente no indivíduo doente, auxiliando essa família de maneira mais contextualizada e compreendida dentro das relações familiares, tanto em situação de doença como em situação de saúde.

É primordial visualizar a atenção domiciliária como uma atividade que se constitui com o intuito de subsidiar a intervenção no processo saúde-doença de indivíduos e famílias, e o planejamento de ações visando à promoção de saúde destes e da coletividade.

O encontro entre família e trabalhadores, como um espaço ético - abarcando os princípios de autonomia, confiança e co-responsabilização no processo de cuidados à saúde da família 35 significa compartilhamento de responsabilidades, então, se faz necessário esclarecer que não é objetivo repassar para a família o cuidado, já que o sistema de saúde não está tendo condições de fornecê-lo, mas, sim, construir uma assistência em que as respostas se situem o mais próximo possível do nível em que se encontram as necessidades e as possibilidades de atendê-las. Nesse sentido, autores como Pereira 30 e Furtado 32 aler- 
tam sobre as potências que o domicílio possibilita para a mudança de concepções e, portanto, do processo de trabalho. Essa prática poderá contribuir com possibilidades de operar os serviços de saúde de forma a estabelecer uma relação acolhedora, marcada pelo compromisso e responsabilização pela saúde dos usuários, pela preocupação com o desenvolvimento da autonomia do usuário, visando que este vá se apropriando das diversas tecnologias, possibilitando-lhe cada vez mais ir resolvendo ou minimizando parte daquilo que lhe tem causado sofrimento.

O atributo de articular as ações curativas, preventivas, promocionais, assistenciais e educativas não é exclusivo da assistência domiciliária, pode e deve ocorrer em todos os espaços de assistência à saúde. No entanto, as produções científicas têm ressaltado o domicílio como maior potência para promover essa operacionalização 20,30,32.

Visualizamos esse tipo de assistência como uma forma de aproximação dos trabalhadores com a comunidade, aproveitando este espaço para melhor conhecer e desenvolver o potencial resolutivo de cada família e da ação a ser desenvolvida, além de possibilitar a integração dos trabalhadores da saúde entre si, também.

É importante que os trabalhadores da saúde entendam que têm um papel a cumprir nessa história e que nada se apresenta repentinamente, sem uma determinação social e histórica. Nesse sentido é imprescindível levar em consideração a concepção de que a estrutura assistencial institucional em saúde, em cada momento histórico, resulta de múltiplas determinações: "a) a cultura, o paradigma de ciência das diversas sociedades que, em cada momento histórico, influenciam o modo de entender o processo de saúde-doença, a organização dos serviços e como as doenças são prevenidas e tratadas; b) a história da organização das profissões do campo da saúde; c) os conhecimentos científicos já acumulados e os recursos tecnológicos disponíveis; d) as teorias de organização do trabalho e as características do modo de produção hegemônico; e) o grau de organização político-sindical dos trabalhadores de saúde; f) o arcabouço legislativo relativo ao papel do Estado no setor e as relações de trabalho; $g$ ) as demandas das classes sociais e de grupos em relação à saúde, sua capacidade de influenciar nas decisões e de obter conquistas" 3 (p. 19).

Diante disso, há de se repensar a forma como o trabalho em saúde é desenvolvido e em finalidades diferenciadas do atual modelo de atenção à saúde vigente nas instituições de serviços de saúde.

\section{Considerações finais}

A atenção domiciliária foi configurada, neste texto, como uma estratégia capaz de se apresentar ao mundo do trabalho como uma alternativa de reorganização do sistema de saúde, exeqüível, humanizadora e com potencial de resolutividade.

Refletindo sobre essa prática do trabalho, pode-se constatar que não há um único e restrito objeto de trabalho, pois, ora este é composto por um sujeito carente de cuidados, ora pela sua família. Ao aprofundar as reflexões, embasadas no estudo de diferentes autores, percebe-se que a finalidade da atenção domiciliária que, a princípio, poderia se configurar superficialmente como uma ação imediatista, pontual, engloba no seu interior elementos orientadores para o alcance de necessidades mediatas. Essa prática de trabalho, intitulada atenção domiciliária, integra ações de visita e, também, de internação domiciliária, conforme a necessidade manifesta pela clientela, objeto da ação. Seu desenvolvimento pode ser dado em duas direções: do hospital, em direção ao domicílio, e deste, em direção ao ambiente hospitalar. O que significa dizer que o sistema de saúde local de cada município pode ser organizado de tal forma que tenha a atenção domiciliária como parte de suas ações de saúde e, em que, neste sistema, estejam congregadas diferentes atividades, seja na forma de visita domiciliária com propósitos preventivos e de promoção da saúde, seja na forma de cuidados contínuos no domicílio (internação domiciliária), como o exemplo da Argentina.

No entanto reconhecemos que há uma série de aspectos que funcionam como um entrave para sua concretização prática, apesar de seu ideal teórico, dos quais pode-se destacar a formação dos trabalhadores, a cultura institucional e social e a dificuldade de extrapolar os limites de sua abrangência territorial, quando necessária uma referência a outros serviços.

Nesse sentido, os aspectos ressaltados precisam ser trabalhados e entendidos, ao mesmo tempo, como processuais, pois somente com o transcorrer do tempo vão sendo assimilados e transformados para atingir a finalidade desejada. É importante refletir que para implantação do PSF ou qualquer outra estratégia semelhante, faz-se necessário a compreensão do processo de trabalho e do projeto de saúde com o qual este está comprometido no cenário político-social, pois, sem isto, corre-se o risco de mudar somente o local ou o nome do serviço de assistência sem alterar a lógica que o sustenta.

Acreditamos que uma integração das diversas práticas de trabalhos pode funcionar como ele- 
mento potencializador na mudança de modelo. A atenção domiciliária realizada no PSF pode ser uma das formas de cuidar e educar no domicílio, se agregada ao serviço hospitalar como forma de obter a integralização da atenção e à compreensão do processo de trabalho, refletindo no como, para que e por que se faz.

Acreditamos no impacto que esse tipo de atividade possa gerar na qualidade de vida e saúde da população e, ao mesmo tempo, possibilitando a realização de um trabalho interdisciplinar e integrador, motivador da satisfação pessoal e profissional a todos os envolvidos no processo.

\section{Resumo}

Este texto apresenta uma reflexão sobre a atenção domiciliária enquanto um trabalho em saúde, que vem se expandindo no sistema público e privado, ao mesmo tempo em que discute a atenção domiciliária e a possibilidade da mesma alavancar um impacto significativo na qualidade de vida e na saúde da população. Apresenta a atenção domiciliária como uma possibilidade estratégica de reorganização do Sistema de Saúde, por meio da integração entre os trabalhadores e as instituições de saúde. Também são consideradas os possíveis impactos políticos, econômicos e técnicos da atenção domiciliária no sistema de saúde, nos trabalhadores e nos usuários desse serviço.

Assistência Domiciliar; Sistemas de Saúde; Pessoal de Saúde

\section{Colaboradores}

O artigo foi redigido por N. P. C. Kerber, sob orientação de A. L. Kirchhof e co-orientação de M. R. Cezar-Vaz.

\section{Agradecimentos}

Texto produzido a partir de pesquisa financiada pelo Conselho Nacional de Desenvolvimento Científico e Tecnológico (CNPq).
Ao finalizar esta reflexão, consideramos importante ressaltar que a atenção domiciliária que percebemos como capaz de potencializar a reorganização do atual sistema de saúde não é apenas conceitual, mas operacional. O trabalho desenvolvido na atenção domiciliária, no nosso entendimento, tem uma atuação mais ampliada do que a realização de inquéritos, cadastramentos, controle de faltosos, o que resulta em um serviço com ações pontuais e focalizadas. A atenção domiciliária destina-se a proporcionar ações mais integrais ao indivíduo e à família e, ainda, proporcionar uma integração entre os diversos serviços de saúde.

\section{Referências}

1. Masi D. O futuro do trabalho - fadiga e ócio na sociedade pós-industrial. Brasília: José Olimpio/Universidade de Brasília; 2000.

2. Offe C. Trabalho e sociedade - problemas estruturais e perspectivas para o futuro da sociedade do trabalho. Rio de Janeiro: Tempo Brasileiro; 1989.

3. Pires D. Reestruturação produtiva e trabalho em saúde no Brasil. São Paulo: Annablume; 1998.

4. Possas C. A articulação público-privado e o cuidado com a saúde dos pobres: implicações das políticas de ajuste estrutural na América Latina. In: Eibenschutz C, organizador. Política de saúde: o público e o privado. Rio de Janeiro: Editora Fiocruz; 1996. p. 45-65.

5. Pires D. Novas formas de organização do trabalho em saúde e enfermagem. Rev Baiana Enfermagem 2000; 13:83-92.

6. Vázquez AS. Filosofia da práxis. 4a Ed. Rio de Janeiro: Editora Paz e Terra; 1987.

7. Kirchhof AL. O trabalho da enfermagem: análises e perspectivas. Rev Bras Enfermagem 2003; 56:669-73.

8. Almeida MCP, Rocha SM. O trabalho da enfermagem. São Paulo: Cortez Editora; 1997.

9. Castellanos BEP, Rodrigues AM, Almeida MCP, Rosa MTL, Mendes SASA. Os desafios da enfermagem para os anos 90. In: Anais do Congresso Brasileiro de Enfermagem. Florianópolis: Associação Brasileira de Enfermagem; 1989. p. 147-69. 
10. Leopardi MT, Gelbcke F, Ramos FR. Cuidado: objeto de trabalho ou objeto epistemológico da enfermagem? Texto \& Contexto Enfermagem 2001; 10:32-49.

11. Fialho AVM, Pagliuca LMF, Soares E. Adequação da Teoria do Déficit do Autocuidado no cuidado domiciliar à luz do Modelo de Barnum. Rev Latinoam Enfermagem 2002; 10:715-20.

12. Silva SR, Aguillar OM. Assistência de enfermagem e acompanhamento domiciliar em quimioterapia antineoplásica. Rev Bras Enfermagem 2002; 55:123-7.

13. Paskulin LMG, Dias VRG. Como é ser cuidado em casa: as percepções dos clientes. Rev Bras Enfermagem 2002; 55:140-5.

14. Kerber NPC, Azambuja EP, Soares J, Cardoso VM. Assistência domiciliar: investigando essa prática junto à clientela. Revista da Saúde 2002; 6:85-95.

15. Lacerda MR. Tornando-se profissional no contexto domiciliar: vivência do cuidado da enfermeira. In Anais do 11o Encontro de Enfermagem da Região Sul. Porto Alegre: Associação Brasileira de Enfermagem; 2000. p. 90-3.

16. Silva KL, Leite JCA, Sena RR, Seixas CT. A internação domiciliar e os desafios das relações interpessoais e interprofissionais. Rev Paul Enfermagem 2004; 23:29-36.

17. Hirschfeld MJ, Oguisso T. Visão panorâmica da saúde no mundo e a inserção do Home Care. Rev Bras Enfermagem 2002; 55:452-9.

18. López-Benito I, Baydal R. Home hospitalization: an alternative to conventional hospitalization. Future outline. Rev Neurol 1999; 29:677-9.

19. Sherperd S, Iliffe S. Hospital at home. BMJ 1996; 312:923-4.

20. Trujillo Z, Cardeña CI, Feria CV, Jorge CMC, Pérez JG, Barrera MJ, et al. Atención domiciliaria: un modelo de atención integral. Med Interna Méx 1999; 15(5 Suppl):217-23.

21. Ramallo VJG, Martinez BV, Garcia VR. Hospital at home. Med Clin (Barc) 2002; 118:659-64.

22. Carleti SMM, Rejani MI. Atenção domiciliária ao paciente idoso. In: Papaleo Netto M, organizador. Manual de gerontologia. São Paulo: Editora Atheneu; 1997. p. 415-9.

23. Secretaria Municipal da Saúde. Programa de assistência domiciliar. São Paulo: Secretaria Municipal de Saúde, Prefeitura do Município de São Paulo; s.d.

24. Maidana MC. Normas de internación domiciliaria. Temas Enferm Actual 2001; 9(43 Suppl):24-8.
25. Fracolli LA, Bertolozzi MR. A abordagem do processo saúde-doença das famílias e do coletivo. Temas de caráter introdutório. http://www.ids-saude.org. br/enfermagem (acessado em 15/Mai/2004).

26. Franco TB, Merhy EE. PSF: contradições de um programa destinado à mudança do modelo tecnoassistencial. Campinas: Departamento de Medicina Preventiva e Social, Faculdade de Ciências Médicas, Universidade Estadual de Campinas; 1999.

27. Duarte YAO, Diogo MJD. Atendimento domiciliar: um enfoque gerontológico. São Paulo: Editora Atheneu; 2000.

28. Santos BR, Sagebin HV, Eidt OR, Witt RR. O domínio como espaço do cuidado de enfermagem. In: Anais do 50 Congresso Brasileiro de Enfermagem. Salvador: Associação Brasileira de Enfermagem Seção Bahia; 1998. p. 121-32.

29. Cecílio LCO. Modelos tecno-assistenciais em saúde: da pirâmide ao círculo, uma possibilidade a ser explorada. Cad Saúde Pública 1997; 13:469-78.

30. Pereira MJB. O trabalho da enfermeira no Serviço de Assistência Domiciliar - potência para (re)construção da prática de saúde e de enfermagem [Tese de Doutorado]. Ribeirão Preto: Escola de Enfermagem de Ribeirão Preto, Universidade de São Paulo; 2001.

31. Gallego CF, Sánchez DF, Rodríguez MVM, Casbas TM, Cortés PC, Arribas MCM, et al. Visita domiciliar programada de enfermería a personas mayores de 65 años. http://bvs.isciii.es/mono/pdf/ INVESTEN_02.pdf (acessado em 25/Jul/2004).

32. Furtado JP. A avaliação como dispositivo [Tese de Doutorado]. Campinas: Faculdade de Ciências Médicas, Universidade Estadual de Campinas; 2001.

33. Cotta RMM, Suarez-Varela MM, Cotta Filho JS, Llopis-Gonzalez A, Dias-Ricòs JA, Real ER. La hospitalización domiciliaria ante los cambios demográficos y nuevos retos de salud. Rev Panam Salud Pública 2002; 11:253-61.

34. Albiero CE. Assistência domiciliar como modalidade de atendimento à saúde no contexto da família e das políticas sociais [Dissertação de Mestrado]. Florianópolis: Programa de Pós-graduação em Serviço Social, Universidade Federal de Santa Catarina; 2003.

35. Alonso ILK. Luzes e sombras no ritual do encontro entre o universo profissional e o mundo da intimidade familiar: a intervenção profissional na saúde da família em âmbito domiciliar [Tese de Doutorado]. Florianópolis: Programa de Pós-graduação em Enfermagem, Universidade Federal de Santa Catarina; 2003.

Recebido em 28/Set/2006

Versão final reapresentada em 24/Abr/2007

Aprovado em 29/Jun/2007 